\title{
RNF113A promotes the proliferation, migration and invasion, and is associated with a poor prognosis of esophageal squamous cell carcinoma
}

\author{
LEI WANG $^{1,2}$, ZHICHAO HOU ${ }^{1}$, AYSHAMGUL HASIM ${ }^{3}$, ABULAJIANG ABUDUERHEMAN ${ }^{1}$, HAIPING ZHANG ${ }^{1}$, \\ MADINIYAT NIYAZ ${ }^{4}$, IDIRIS AWUT ${ }^{1}$, HALMURAT UPUR $^{5}$ and ILYAR SHEYHIDIN $^{1}$ \\ Departments of ${ }^{1}$ Thoracic Surgery and ${ }^{2}$ Gastroenterology, The First Affiliated Hospital of Xinjiang Medical University; \\ ${ }^{3}$ Department of Pathology, Medical University of Xinjiang; ${ }^{4}$ Clinical Medical Research Institute, \\ The First Affiliated Hospital of Xinjiang Medical University; ${ }^{5}$ Department of Uyghur Medicine, \\ Xinjiang Medical University, Urumqi, Xinjiang Uygur Autonomous Region 830054, P.R. China
}

Received June 14, 2017; Accepted December 4, 2017

DOI: $10.3892 /$ ijo.2018.4253

\begin{abstract}
Ring finger protein 113A (RNF113A) possesses a $\mathrm{C} 3 \mathrm{HC} 4$ zinc finger domain and this domain is found in E3 ubiquitin ligase and is involved in tumorigenesis. To date, and at least to the best of our knowledge, there are no studies available which have investigated RNF113A in cancer. Thus, this study aimed to explore the role of RNF113A in the development of esophageal squamous cell carcinoma (ESCC). For this purpose, paraffin-embedded samples from 117 patients with ESCC were selected, as well as 41 pairs of fresh-frozen ESCC and adjacent normal tissue samples. RNF113A expression was examined by immunohistochemistry and reverse transcriptionquantitative PCR (RT-qPCR). RNF113A was overexpressed or silenced in the EC9706 and Eca109 cells. The cells were examined for cell cycle progression, apoptosis, invasiveness and migration. Xenograft tumors were also created in mice using the Eca109 cells. Tumor differentiation $(\mathrm{P}=0.008)$ and $\mathrm{T}$ classification $(\mathrm{P}<0.001)$ were found to be significantly associated with RNF113A expression. No statistically significant
\end{abstract}

Correspondence to: Dr Ilyar Sheyhidin, Department of Thoracic Surgery, The First Affiliated Hospital of Xinjiang Medical University, 137 Liyushan Road, Urumqi, Xinjiang Uygur Autonomous Region 830054, P.R. China

E-mail: ilyarsha@sina.com

Abbreviations: EC, esophageal cancer; ESCC, esophageal squamous cell carcinoma; OS, overall survival; UPP, ubiquitin-proteasome pathway; EMT, epithelial-mesenchymal transition; TTD, trichothiodystrophy; MDS, myelodysplastic syndrome; IHC, immunohistochemistry; FBS, fetal bovine serum; MOI, multiplicity of infection; RIPA, radioimmunoprecipitation assay; PVDF, polyvinylidene fluoride; FCM, flow cytometry; PBS, phosphate-buffered saline; PI, propidium iodide; TV, tumor volume; UVA, ultraviolet A

Key words: ring finger protein 113A, prognosis, esophageal squamous cell carcinoma, migration, invasion, proliferation association was observed between RNF113A expression and sex, age, histological type, tumor location and lymph node metastasis ( $\mathrm{N}$ classification). Kaplan-Meier analysis revealed that the patients with ESCC with ahigh expression of RNF113A had a lower survival rate than those with a low expression $(\mathrm{P}=0.002)$. Multivariate analysis revealed that $\mathrm{RNF} 113 \mathrm{~A}$ expression $(\mathrm{HR}=2.406$; 95\% CI, 1.301-4.449, $\mathrm{P}=0.005)$ was independently associated with overall survival in patients with ESCC. The overexpression of RNF113A promoted proliferation, migration, and invasiveness of ESCC cell lines in vitro, and RNF113A silencing reversed these malignant behaviors. RNF113A knockdown inhibited tumor growth in vivo. Thus, these results indicate that RNF113A promotes the proliferation, migration and invasiveness of ESCC cell lines. RNF113A expression in ESCC is this associated with a poor prognosis of affected patients.

\section{Introduction}

Esophageal cancer (EC) is the sixth leading cause of cancer-related mortality worldwide (1). In China, EC is ranked as the fourth leading cause of cancer-related mortality, and an estimated 218,957 individuals succumbed to the disease in China in 2011 (2). In China, the majority of EC cases are esophageal squamous cell carcinoma (ESCC) (3). ESCC is usually diagnosed at an advanced stage and its prognosis is poor (4). Approximately $80 \%$ of ESCC cases occur in the Central and South-East Asian region. China alone contributes to more than half of the global cases (53\%, 210,000 cases) (5). A distinctive characteristic of EC in China is its uneven burden between rural and urban areas. Indeed, the rates of EC are 2- to 10-fold higher in rural areas compared with urban areas (2).

Kazakh patients show particularly high morbidity (68.88/100,000) and mortality rates from ESCC, particularly in the Tuoli (Xinjiang) Province, which exhibits the highest incidence $(155.8 / 100,000)$ of EC worldwide. The incidence of ESCC among Kazakh patients is 4-fold higher than the general incidence in China (14.95/100,000) (6). 
The treatment of ESCC involves a multidisciplinary approach combining surgery, chemotherapy and radiation therapy (7). Nevertheless, even in developed countries, the 5-year overall survival (OS) of patients with ESCC is only $15 \%$ (4), stressing the need for novel markers for screening and prognosis of ESCC.

The ubiquitin-proteasome pathway (UPP) consists of enzyme 1 (E1; or ubiquitin activating enzyme), enzyme 2 (E2; or ubiquitin-conjugating enzyme), enzyme 3 (E3; or ubiquitin ligase) and $26 \mathrm{~S}$ proteasome (8). The UPP influences and regulates apoptosis and plays a central role in the regulation of ubiquitin binding and substrate specificity (9). To date, only E3 ligases of the RING-type have been found to participate in Snail and Twist ubiquitination, which play important roles in epithelial-mesenchymal transition (EMT) $(10,11)$. The degradation of most EMT factors is strictly dependent upon multi-subunit RING-type E3s (11).

Ring finger protein 113A (RNF113A), previously known as ZNF183, is located on chromosome Xq24.9 (12). RNF113A has two conserved zinc finger domains: AC3H1-type zinc finger domain and a $\mathrm{C} 3 \mathrm{HC} 4$ zinc finger domain. Zinc finger domains are shared by various tumor suppressors, DNA repair proteins and cytokine receptor-associated molecules (13). The C3H1-type RNF113A zinc finger domain is often found in RNA-binding proteins involved in splicing, while zf-C3HC4 is considered to be an ubiquitin-related structural domain (14) and is often found in E3 ubiquitin ligases (15).

A number of studies have indicated that there are close associations between ubiquitin ligase and the occurrence, development and metastasis of cancer $(16,17)$. Previous studies have found that the disruption of RNF113A in zebrafish (Danio rerio) by transgenic insertional mutagenesis results in a small and slightly necrotic head, small eyes, pericardial edema and an underdeveloped liver and gut $(12,18)$. In Caenorhabditis elegans, the knockdown of RNF113 has been shown to sensitize the cells to ultraviolet A (UVA)induced DNA damage and is required for RAD51 focus formation during DNA interstrand crosslink repair (19). Corbett et al (12) and Pellagatti et al (20) reported that RNF113A mutations are associated with non-photosensitive trichothiodystrophy (TTD). RNF113A may regulate neuronal differentiation in the human central nervous system (15). Pellagatti et al (20) studied gene expression profiles in the neutrophils of 21 patients with myelodysplastic syndrome (MDS) using cDNA microarrays comprising 6,000 human genes, and found that ZNF183 was one of the most upregulated genes in MDS (20). Therefore, it can be hypothesized RNF113A is associated with the development and progression of ESCC.

To date, and at least to the best of our knowledge, there are no available studies on the role of RNF113A in cancer. Therefore, this study aimed to explore the role of RNF113A in the development of ESCC by comparing the expression of RNF113A in Kazakh patients with ESCC and paired adjacent non-tumor tissues. The biological roles of RNF113A were also investigated by inducing either the overexpression or knockdown of RNF113A in the ESCC cell lines, Eca109 and EC9706. Finally, xenograft tumors in athymic nude mice were created out to assess the tumorigenic effect of RNF113A in vivo.

\section{Materials and methods}

Study design, patients and specimens. This study was approved by the Medical Ethics Committee of the First Affiliated Hospital of Xinjiang Medical University, Urumqi, China. Informed consent was obtained from all subjects prior to obtaining the samples. Paraffin-embedded samples from 117 Kazakh patients with ESCC treated at our hospital from March 2010 to December 2014, were selected. Paired ESCC and adjacent normal tissues were available for 41 patients. None of the patients had received chemoradiotherapy or radiotherapy prior to surgery. ESCC was staged and graded according to the International Union Against Cancer (21). The patients were followed-up by consulting their charts and through telephonic monitoring. Follow-up data were available for periods ranging from 3 months to 6.8 years (median, 20.8 months).

Immunohistochemistry (IHC). The samples were incubated with anti-human RNF113A antibody (1:50 dilution, HPA000160; Sigma, St. Louis, MO, USA) overnight at $4^{\circ} \mathrm{C}$, and then with biotinylated secondary antibody (PV6001; Beijing Zhongshan Golden Bridge Biotechnology Co., Ltd., Beijing, China). IHC analysis was carried out according to previously described methods (22). The staining intensity was assessed using 5 randomly selected high-power fields (x400 magnification). The staining was evaluated by two independent pathologists who were blinded to the clinical characteristics of the patients. Any differences in opinion were resolved by consensual agreement, based on the criteria by Sinicrope et al (23). Staining was assessed with regard to intensity ( 0 , no intensity; 1 , weak intensity; 2 , moderate intensity; and 3, strong intensity) and the percentage of positive cells $(0,<5 \%$; 1 , between 5 and $25 \%$; 2 , between 26 and $50 \%$; and $3,>50 \%)$. The patients were classified into 2 groups according to the total score (i.e., staining intensity score + positive cell score): the low expression group (total score of 0-2) and the high expression group (total score of 3-9).

Cell culture. The human ESCC cell lines, EC9706 and Eca109, were provided by Wuhan University (originally obtained from the China Center for Type Culture Collection, Wuhan, China). These two cell lines are frequently used to study the the malignant behavior of ESCC cells (3,16,24-28). The cells were cultured in Roswell Park Memorial Institute (RPMI)-1640 medium supplemented with $10 \%$ fetal bovine serum (FBS) (both from Thermo Fisher Scientific, Waltham, MA, USA) and $1 \%$ penicillin/streptomycin at $37^{\circ} \mathrm{C}$ in a $5 \% \mathrm{CO}_{2}$ humidified incubator.

shRNA synthesis and lentivirus packaging and transduction. The shRNA sequences against RNF113A (GenBank no. NC_000023) (Table I) and the scramble sequence (5'-TTC TCC GAA CGT GTC ACG T-3') were synthesized by GeneChem (Shanghai, China). Lentiviral vectors of RNF113A were constructed by GeneChem using the GV248 vector (GeneChem). This vector (batch \#CON077) contains hU6, MCS, ubiquitin, EGFP, IRES and puromycin sequences. The ESCC cells $\left(3-5 \times 10^{4} / \mathrm{ml}\right)$ were transduced with lentivirus-mediated RNF113A shRNA or scramble-shRNA [multiplicity of infection (MOI) of 20], according to the 
Table I. Oligonucleotide shRNA sequences of RNF113A.

\begin{tabular}{|c|c|c|c|c|}
\hline RNF113A-shRNA & $5^{\prime}$ & Stem & Loop & Stem \\
\hline RNF113A-shRNA1 & Ccgg & GCGTCTTCAATCCAGCGAAAGAATT & CTCGAG & AATTCTTTCGCTGGATTGAAGACGC TTTTTg \\
\hline RNF113A-shRNA2 & aattcaaaaa & GCGTCTTCAATCCAGCGAAAGAATT & CTCGAG & AATTCTTTCGCTGGATTGAAGACGC \\
\hline
\end{tabular}

RNF113A, ring finger protein 113A.

manufacturer's instructions. The cells were harvested $72 \mathrm{~h}$ after transduction for western blot analysis. For the subsequent experiments, we selected RNF113A-shRNA2 as it was more effective than RNF113A-shRNA1 in decreasing the expression of RNF113A (Fig. 2A).

pcDNA3.1-RNF113A overexpression. The eukaryotic expression vector, pcDNA3.1, overexpressing RNF113A (sense, 5'-TCC GCTCGAGATGATGGACTTGGAGCTGCC-3' and antisense, 5'-ATGGGGTACCGAGTTTTTCTTAACATCTGGC-3') was constructed by GeneChem. Polymerase chain reaction (PCR) was used to identify the recombinant clones. Sequencing was used to confirm the presence of the insert as well as the sequence and orientation of the insert. The ESCC cells were transfected with pcDNA3.1 (empty vector) and pcDNA3.1-RNF113A overexpression vector using Lipofectamine 2000 (Thermo Fisher Scientific).

Reverse transcription-quantitative PCR (RT-qPCR). Total RNA was isolated from 41 pairs of frozen ESCC and adjacent normal tissue samples, and from tumor xenografts (please see description of mouse model below) using TRIzol reagent (Thermo Fisher Scientific). The concentration and purity of the RNA in each sample was determined by measuring he absorbance at 260 and $280 \mathrm{~nm}$ using a NanoDrop 2000 spectrophotometer (Thermo Fisher Scientific). Total RNA was reverse transcribed into single-stranded cDNA using the RT reagent kit (Takara Bio, Otsu, Japan). The PCR primers were as follows: RNF113A forward, 5'-TCC GCT CGA GAT GAT GGA CTT GGA GCT GCC-3' and reverse, 5'-ATG GGG TAC CGA GTT TTT CTT AAC ATC TGG C-3'. Quantitative PCR was performed using the IQ5 system (Bio-Rad, Hercules, CA, USA) and SYBR Premix Ex Taq (Takara Bio), according to the manufacturer's instructions. The relative expression levels of RNF113A were normalized to those of $\beta$-actin (primers used were: forward, 5'-CTA AGT CAT AGT CCG CCT AGA AGC A-3' and reverse, 5'-TGG CAC CCA GCA CAA TGA A-3'). The reaction conditions for RNF113A were as follows: $95^{\circ} \mathrm{C}$ for $3 \mathrm{~min}$, and 40 cycles at $95^{\circ} \mathrm{C}$ for $10 \mathrm{sec}$ followed by $59.2^{\circ} \mathrm{C}$ for $30 \mathrm{sec}$. The $2^{-\Delta \Delta \mathrm{Ct}}$ method was used to calculate the relative mRNA expression of the target gene.

Western blot analysis. The cells were harvested $72 \mathrm{~h}$ after transduction in radio-immunoprecipitation assay (RIPA) lysis buffer (Bioteke, Beijing, China). Proteins were quantified by BCA assay (Beyotime Institute of Biotechnology, Shanghai, China), and $50 \mu \mathrm{g}$ of proteins were subjected to $10 \%$ sodium dodecyl sulfate-polyacrylamide gel electrophoresis (SDS-PAGE). Proteins were transferred onto polyvinylidene fluoride (PVDF) microporous membranes (Millipore Corp., Billerica,
Table II. Association between RNF113A expression and clinicopathological characteristics of patients with ESCC.

\begin{tabular}{|c|c|c|c|c|}
\hline \multirow[b]{2}{*}{ Variable } & \multicolumn{3}{|c|}{ RNF113A expression } & \multirow[b]{2}{*}{ P-value } \\
\hline & No. & $\begin{array}{c}\text { Positive } \\
(n=75)\end{array}$ & $\begin{array}{c}\text { Negative } \\
(n=42)\end{array}$ & \\
\hline Age (years) & & & & 0.086 \\
\hline$<60$ & 53 & $38(71.7)$ & $15(28.3)$ & \\
\hline$\geq 60$ & 64 & $37(57.8)$ & $27(42.2)$ & \\
\hline Sex & & & & 0.457 \\
\hline Male & 87 & $55(63.2)$ & $32(36.8)$ & \\
\hline Female & 30 & $20(66.7)$ & $10(33.3)$ & \\
\hline Differentiation & & & & 0.008 \\
\hline Well & 26 & $12(46.2)$ & $14(53.8)$ & \\
\hline Moderate & 57 & $34(59.6)$ & $23(40.4)$ & \\
\hline Poor & 24 & $21(87.5)$ & $3(12.5)$ & \\
\hline $\mathrm{T}$ classification & & & & $<0.001$ \\
\hline $\mathrm{T} 1-\mathrm{T} 2$ & 54 & $19(35.2)$ & $35(64.8)$ & \\
\hline T3-T4 & 63 & $56(88.9)$ & $7(11.1)$ & \\
\hline $\mathrm{N}$ classification & & & & 0.11 \\
\hline No & 76 & $43(56.6)$ & $33(43.4)$ & \\
\hline N1 & 24 & $15(62.5)$ & $9(37.5)$ & \\
\hline $\mathrm{N} 2$ & 11 & $10(90.9)$ & $1(9.1)$ & \\
\hline N3 & 6 & $5(83.3)$ & $1(16.7)$ & \\
\hline Histological type & & & & 0.416 \\
\hline Protruding type & 17 & $8(47.1)$ & $9(52.9)$ & \\
\hline Ulcerative type & 69 & $45(65.2)$ & $24(34.8)$ & \\
\hline Fungating type & 13 & $9(69.2)$ & $4(30.8)$ & \\
\hline Medullary type & 18 & $13(72.2)$ & $5(27.8)$ & \\
\hline Tumor location ${ }^{\mathrm{a}}$ & & & & 0.762 \\
\hline Upper & 11 & $8(72.7)$ & $3(27.3)$ & \\
\hline Middle & 59 & $39(66.1)$ & $20(33.9)$ & \\
\hline Lower & 47 & $29(61.7)$ & $18(38.3)$ & \\
\hline
\end{tabular}

It should be noted that only the cases with clear information were included

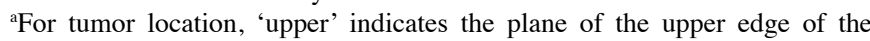
sternum handle to the bifurcation plane of the trachea; 'middle' indicates the upper part of the whole length from the bifurcation plane of the trachea to the junction of the esophagus and the stomach; and 'lower' indicates the lower part of the whole length from the bifurcation plane of the trachea to the junction of the esophagus and stomach. All data are presented as $\mathrm{n}(\%)$. Values in bold font indicate statistical significance. RNF113A, ring finger protein 113A; ESCC, esophageal squamous cell carcinoma.

MA, USA) and the blots were probed with rabbit polyclonal antibody against RNF113A (ab85797; Abcam, Cambridge, MA, USA) at a concentration of $1 \mu \mathrm{g} / \mathrm{ml}$. $\beta$-actin (BA2305; 
Wuhan Boster Bio-Engineering Co., Ltd., Wuhan, China) was used as an internal control. Mouse anti-rabbit secondary antibody (31464; Thermo Fisher Scientific). Chemiluminescence substrate (Thermo Fisher Scientific) was added to visualize the bands, as previously described (22). The integrated optical density of the target proteins was quantified using ImageJ software (National Institutes of Health, Bethesda, MD, USA).

Analysis of the cell cycle and apoptosis. Cell cycle progression and apoptosis were analyzed by flow cytometry (FCM). For cell cycle analysis, the cells were washed with pre-iced phosphate-buffered saline (PBS) twice and fixed with $70 \%$ cold ethanol at $4^{\circ} \mathrm{C}$ overnight. Following incubation with RNase for $1 \mathrm{~h}$ at $4^{\circ} \mathrm{C}$, the cells were stained with $2 \mu \mathrm{l}$ of propidium iodide (PI) $(500 \mathrm{mg} / \mathrm{ml})$ for $15 \mathrm{~min}$, and analyzed using a Cytomics FC500 flow cytometer (Beckman Coulter, Brea, CA, USA). For apoptosis analysis, an Annexin V-FITC apoptosis detection kit was used (Thermo Fisher Scientific). Briefly, the cells were washed twice with iced PBS and resuspended in $400 \mu \mathrm{l}$ of $1 \mathrm{X}$ binding buffer at a concentration of $1 \times 10^{6} \mathrm{cells} / \mathrm{ml}$. A volume of $5 \mu 1$ of the Annexin V-FITC solution and $2 \mu \mathrm{l}$ of PI was then mixed with the cells. The cells were then incubated $15 \mathrm{~min}$ at $4^{\circ} \mathrm{C}$ in the dark. Cell staining was detected using a Cytomics FC500 flow cytometry system (Beckman Coulter).

Cell invasion and migration. The cells at $5 \times 10^{5}$ cells/well were seeded on a fibronectin-coated polycarbonate membrane insert in a Transwell chamber (Corning Inc., Corning, NY, USA). RPMI-1640 supplemented with 10\% FBS was added to the lower chamber. The cells that adhered to the upper surface of the chamber were wiped with a cotton swab. The number of migrated cells was counted under a light microscope (Olympus, Tokyo, Japan) in 5 random fields. For the Matrigel invasion assay, inserts pre-coated with Matrigel (40 $\mu 1,1 \mathrm{mg} / \mathrm{ml}$; BD Biosciences, Franklin Lakes, NJ, USA) were used for invasion assays and incubated at $37^{\circ} \mathrm{C}$ for $6 \mathrm{~h}$.

Wound healing assay. The wound healing assay was carried out to analyze cell migration. The cells were plated in a 6 -well plate at $5 \times 10^{5}$ cells/well. Upon confluent growth, scrape wounds were made using a $10-\mu 1$ pipette tip. The cells were photographed at $0,24,48$ and $72 \mathrm{~h}$ using an inverted fluorescence microscope (Olympus). The wound closure rate was calculated as follows: [Cell-free distance $(0 \mathrm{~h})$-cell-free distance $(24 / 48 / 72 \mathrm{~h})] /$ cell-free distance $(0 \mathrm{~h})$, as previously described $(29,30)$.

Xenograft tumor assays using athymic nude mice. All animal experiments were approved by the Animal Ethics Committee of our hospital. Female 4-6-week-old BALB/c nude mice (weighing, 14-16 g) $(\mathrm{n}=12)$ were purchased from Charles River Laboratories (Beijing, China) and raised in a sterile environment. The mice were divided into 3 groups ( $\mathrm{n}=4$ /group) as follows: the group injected with Eca109 cells, the group injected with Eca109 cells transduced with RNF113A-shRNA2, and the group injected with Eca109 cells transduced with scrambleshRNA. The cells were injected at $4 \times 10^{6}$ cells/mouse into the right flank. Tumor dimensions were measured by calipers every 7 days, and tumor volume (TV) was calculated each week according to the formula: TV $\left(\mathrm{mm}^{3}\right)=$ length $\mathrm{x}$ width ${ }^{2} \mathrm{x} 0.5$. Tumors were removed and weighed 28 days after cell injection. Part of the tumor tissue was cryopreserved in liquid nitrogen for the analysis of RNF113A mRNA expression by RT-qPCR. The remaining tissues were paraffin-embedded for immunohistochemical analysis of RNF113A.

Statistical analysis. Data were analyzed using SPSS 17.0 software (IBM, Armonk, NY, USA). The results are presented as the means \pm standard deviation (SD). The Student's $t$ test and one-way ANOVA were used to evaluate the differences among groups. The LSD test was used following ANOVA. The Chi-square test and Fisher's exact test were used to analyze the association between RNF113A expression and clinicopathological characteristics. Survival curves were plotted using the Kaplan-Meier method and compared with the log-rank test. Univariate and multivariate analyses of survival were performed by Cox regression. Two-sided P-values $<0.05$ were considered to indicate statistically significant differences.

\section{Results}

RNF113A is significantly upregulated inESCC and is associated with a poor prognosis. RNF113A was mainly localized in the cytoplasm and nucleus of the cancer cells (Fig. 1A). RNF113A expression was positive in $64.1 \%$ (75/117) of the ESCC samples. Moreover, RNF113A expression was extremely low or hardly detectable in the adjacent non-tumor tissues. In addition, RNF113A mRNA expression in the 41 fresh-frozen ESCC cases was higher (cancer/normal ratio $>1.0)$ in $73 \%$ (30/41) of the samples when compared with the adjacent non-tumor tissues, with the mean expression level of $1.15 \pm 0.66$ in ESCC and $0.67 \pm 0.66$ in their counterparts $(\mathrm{P}<0.001)$ (Fig. 1B).

The associations between RNF113A expression and the clinicopathological characteristics were analyzed (Table II). Tumor differentiation $(\mathrm{P}=0.008)$ and $\mathrm{T}$ classification $(\mathrm{P}<0.001)$ were significantly associated with RNF113A expression. RNF113A was predominantly upregulated in late-stage, but not early-stage tumor tissues. No statistically significant association was observed between RNF113A expression and sex, age, histological type, tumor location and lymph node metastasis ( $\mathrm{N}$ classification) (all $\mathrm{P}>0.05$ ).

Fig. 1C shows that survival was improved among patients with a low RNF113A expression in their tumors compared with patients with a high RNF113A expression in their tumors $(\mathrm{P}=0.002)$. Multivariate analysis revealed that $\mathrm{RNF} 113 \mathrm{~A}$ expression (HR=2.406; 95\% CI, 1.301-4.449, $\mathrm{P}=0.005)$ and lymph node metastasis $(\mathrm{HR}=3.219,95 \%$ CI, 1.894-5.469, $\mathrm{P}<0.001)$ were independently associated with overall survival in Kazakh patients with ESCC (Table III).

Effects of knockdown or the overexpression of RNF113A on cell cycle distribution and the apoptosis of Eca109 and EC9706 cells. Fig. 2 shows the effects of the knockdown or overexpression of RNF113A on RNF113A protein expression in human Eca109 and EC9706ESCC cells. RNF113A protein expression was lower in the cells transfected with RNF113A-shRNA1 and RNF113A-shRNA2 than in the untransfected Eca109 and EC9706 cells and scramble-shRNA cells (all $\mathrm{P}<0.01$ ) (Fig. 2A). RNF113A protein expression was 
A
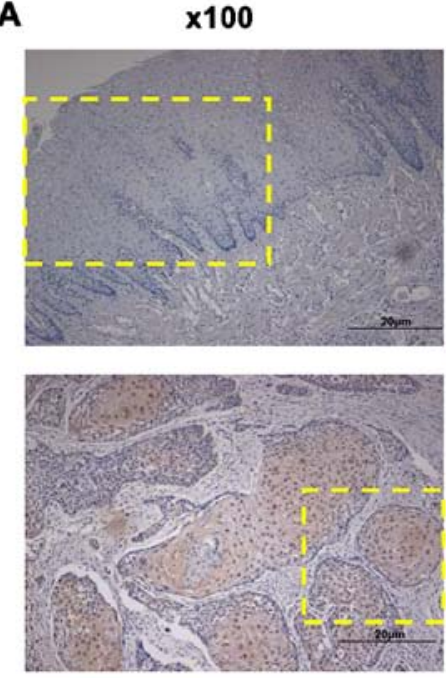

B

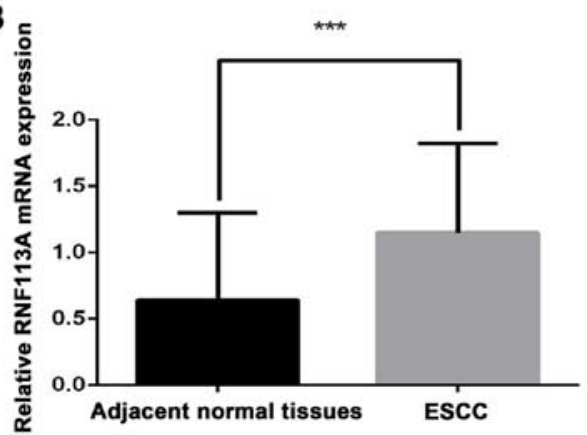

$\times 200$
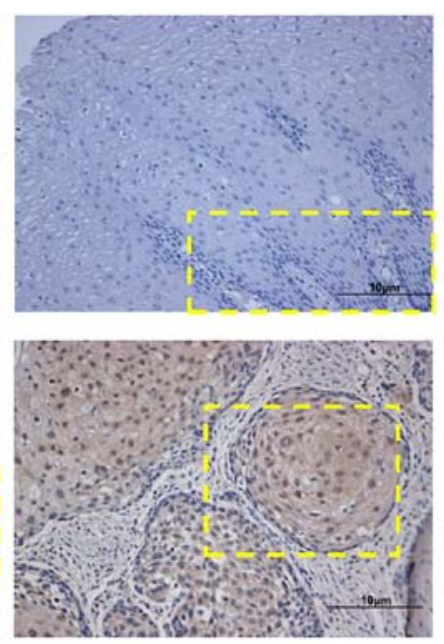

$\times 400$

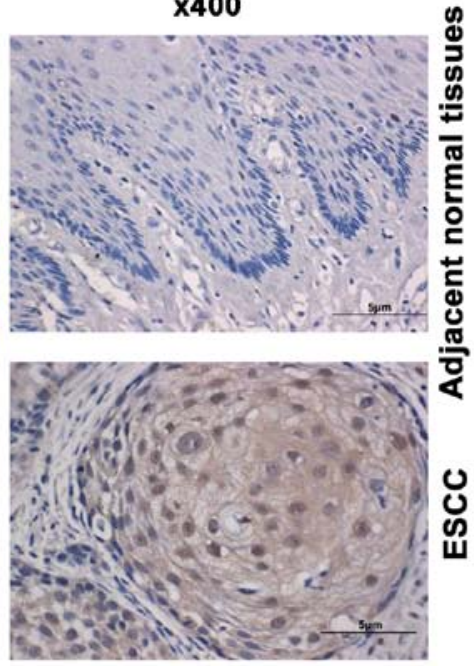

C

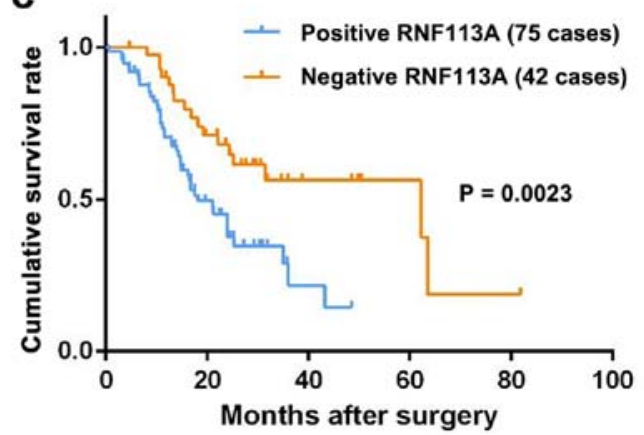

Figure 1. Ring finger protein 113A (RNF113A) expression in esophageal squamous cell carcinoma (ESCC) compared with adjacent normal tissues. RNF113A expression was significantly associated with a poor prognosis. (A) RNF113A expression in ESCC and adjacent normal tissues was determined by immunohistochemistry. The insets with yellow dotted lines the areas which are magnified from the panels on the left. (B) Relative RNF113A mRNA expression in ESCC $(\mathrm{n}=41)$ and adjacent normal tissues $(\mathrm{n}=41)$ was assessed by RT-qPCR. Data are presented as the means \pm standard deviation $(\mathrm{SD}){ }^{* * *} \mathrm{P}<0.001$. $(\mathrm{C}) \mathrm{Kaplan-Meier}$ analysis demonstrated that patients with ESCC and with a high RNF113A expression had a lower overall survival than those with a low RNF113A expression (log-rank test, $\mathrm{P}=0.0023)$.

higher in the RNF113A-overexressing cells than in the untransfected Eca109 and EC9706 cells and empty vector-transfected cells (all $\mathrm{P}<0.001)$ (Fig. 2B).

Fig. 3 shows that cell numbers were significantly increased in the G0/G1 phase and decreased in the $S$ phase and G2/M phase in the cells transfected with RNF113A-shRNA compared with the untransfected Eca109 and EC9706 cells and scramble-shRNA cells (all $\mathrm{P}<0.05$ ). It can be seen that the cell numbers were significantly decreased in the G0/G1 phase and increased in the $\mathrm{G} 2 / \mathrm{M}$ phase in the cells transfected with the pCDNA3.1-RNF113A overexpression vector compared with the empty vector-transfected group and untransfected Eca109 and EC9706 cells. Therefore, the overexpression of RNF113A promoted ESCC cell proliferation.

Apoptosis was also increased when RNF113A was knocked down (all $\mathrm{P}<0.050$ ) (Fig. 4). The overexpression of RNF113A did not lead to changes in apoptosis compared with the controls ( $\mathrm{P}>0.05)$ (Fig. 4).

Effects of the knockdown and overexpression of RNF113A on the migration and invasion of ESCC cells in vitro. In the Transwell assay, the numbers of migrating cells were decreased in the RNF113A-shRNA1 and RNF113A-shRNA2 groups compared with the untransfected Eca109 and EC9706 cells and scramble-shRNA-transfected cells (all $\mathrm{P}<0.001$ ) (Fig. 5). However, the numbers of migrating cells were increased in the RNF113A-overexressing cells compared with the untransfected Eca109 and EC9706 cells and empty vector-transfected cells (all $\mathrm{P}<0.001)$ (Fig. 5).

The knockdown of RNF113A led to a marked decrease in the invasiveness of the Eca109 $(\mathrm{P}<0.01)$ and EC9706 $(\mathrm{P}<0.001)$ cells (Fig. 6). The overexpression of RNF113A significantly increased the invasiveness of the Eca109 and in EC9706 cells (all $\mathrm{P}<0.001$ ) (Fig. 6).

The wound healing assay also revealed that the knockdown of RNF113A inhibited the migration of the Eca109 $(\mathrm{P}<0.05)$ and EC9706 $(\mathrm{P}<0.05)$ cells, compared with the untransfected Eca109 and EC9706 cells and scramble-shRNA-transfected cells (Fig. 7).

Knockdown of RNF113A suppresses tumor growth in a nude mouse tumor xenograft model with Ecal09 cells. All nude mice developed tumors; however, the tumors formed from the scramble-shRNA-transfected cells grew more rapidly than those from the RNF113A-shRNA-transfected cells. The tumors formed from the RNF113A-shRNA-transfected cells were significantly lighter and smaller than those from the scramble-shRNA-transfected cells and Eca109-transfected 
A

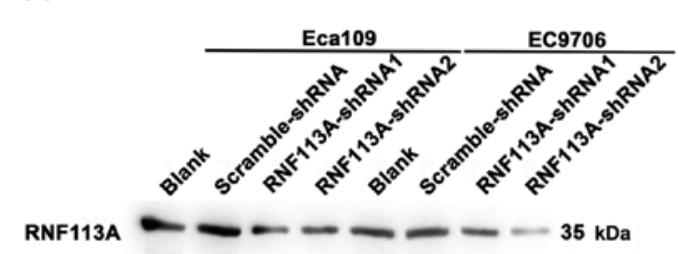

k-actin

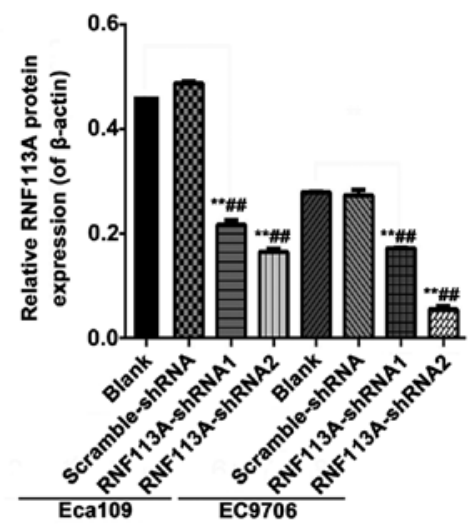

B
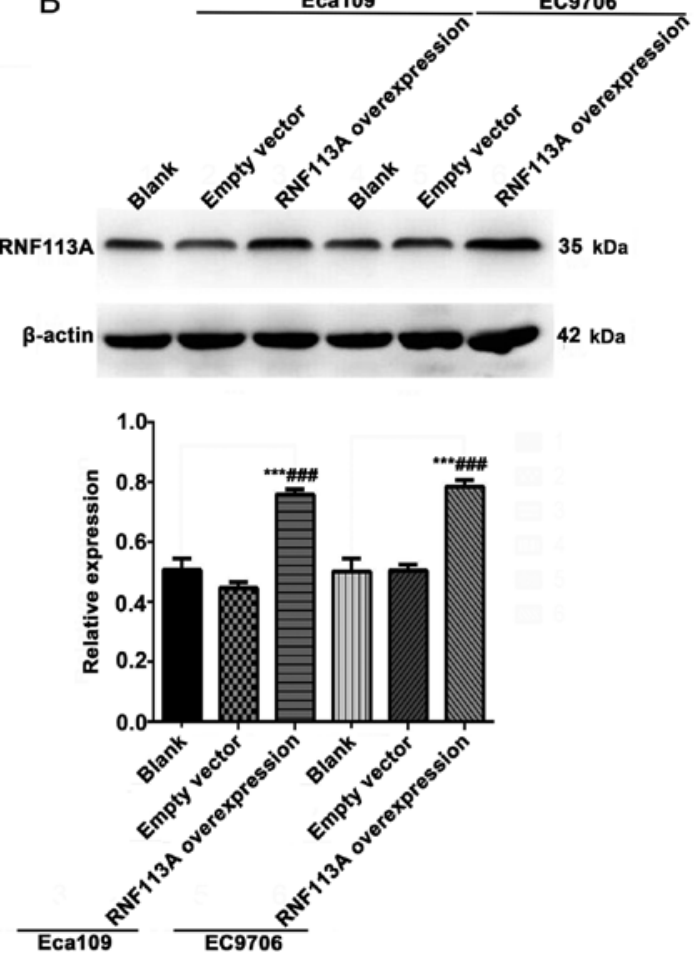

Figure 2. Effects of the knockdown or overexpression of ring finger protein 113A (RNF113A) on RNF113A protein expression in human esophageal squamous cell carcinoma (ESCC) Eca109 and EC9706 cells. (A) Eca109 and EC9706 cells were transfected with lentivirus-mediated RNF113A-shRNA1, RNF113A-shRNA2, and scramble-shRNA for $72 \mathrm{~h}$. (B) Eca109 and EC9706 cells were transfected with empty vector (pcDNA3.1) or RNF113A overexpression vector for $72 \mathrm{~h}$ Protein expression was determined by western blot analysis. $\beta$-actin was used as an internal control. Data are presented as the means \pm SD of 3 independent experiments performed in triplicate. ${ }^{* *} \mathrm{P}<0.01$ and ${ }^{* * * *} \mathrm{P}<0.001$ vs. blank group; ${ }^{\# \#} \mathrm{P}<0.01$ and ${ }^{\# \# \#} \mathrm{P}<0.001$ vs. scramble-shRNA or empty vector group.

\section{Eca109}

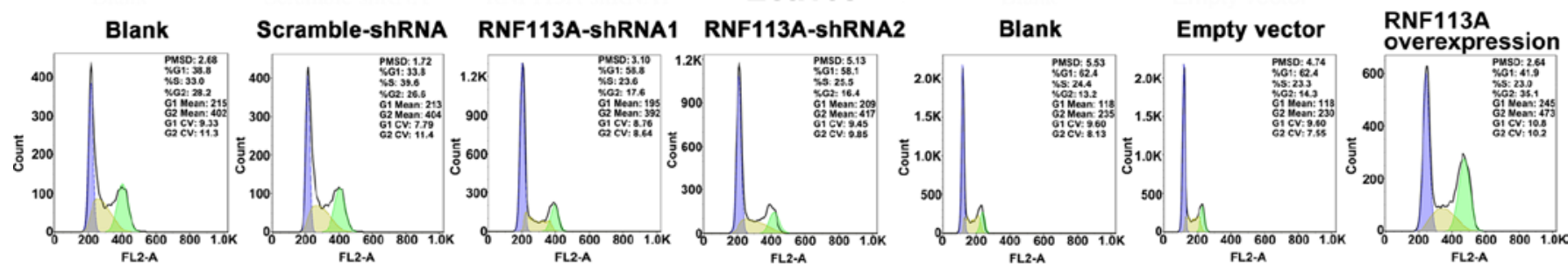

EC9706

Blank Scramble-shRNA RNF113A-shRNA1 RNF113A-shRNA2

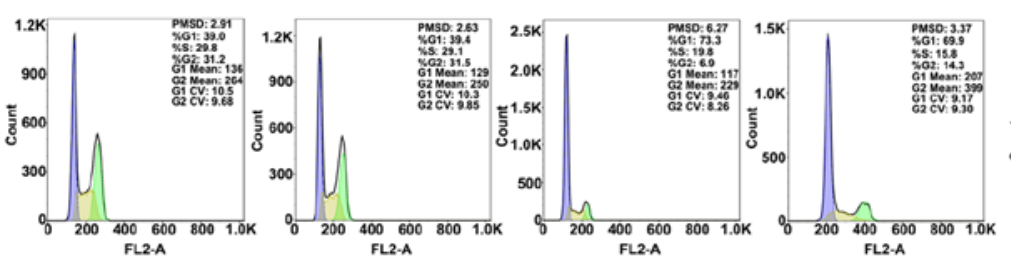

Eca109

Eca109

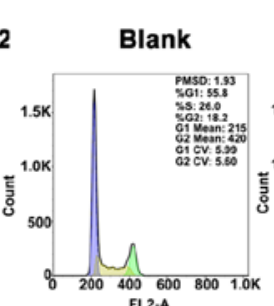

EC9706

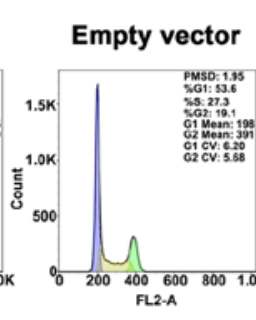

EC9706
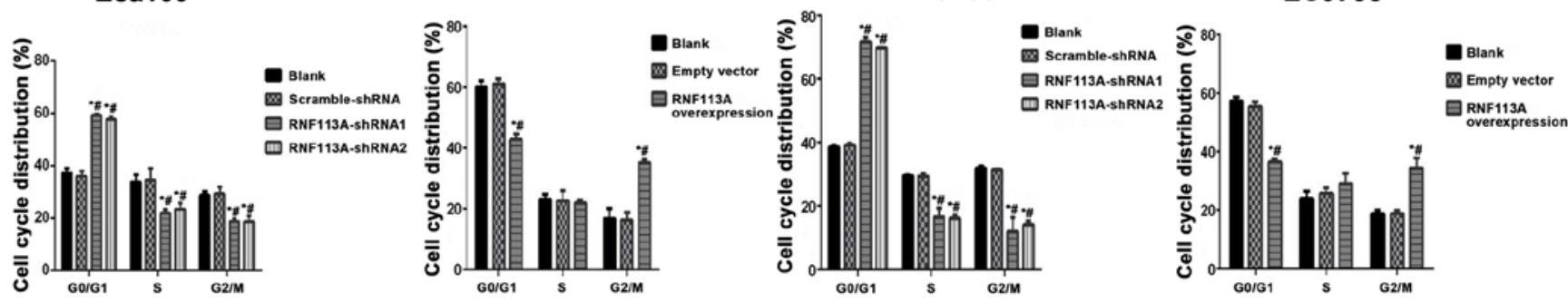

Figure 3. Effects of the knockdown or overexpression of ring finger protein 113A (RNF113A) on cell cycle distribution in Eca109 and EC9706 cells. Eca109 and EC9706 cells were transfected with lentivirus-mediated RNF113A-shRNA1, RNF113A-shRNA2, and scramble-shRNA for 72 h. Eca109 and EC9706 cells were transfected with empty vector (pcDNA3.1) or RNF113A overexpression vector for $72 \mathrm{~h}$. Cell cycle distribution was determined by flow cytometry using propidium iodide (PI) staining. Data are presented as the means \pm SD of 3 independent experiments performed in triplicate. ${ }^{*} \mathrm{P}<0.05$ vs. blank group; ${ }^{\#} \mathrm{P}<0.05$ vs. scramble-shRNA or empty vector. 
Table III. Univariate and multivariate Cox regression analyses of the clinicopathological variables and cumulative survival of the patients with ESCC.

\begin{tabular}{|c|c|c|c|c|c|c|}
\hline \multirow[b]{2}{*}{ Covariant } & \multicolumn{3}{|c|}{ Univariate analysis } & \multicolumn{3}{|c|}{ Multivariate analysis } \\
\hline & HR & $95 \% \mathrm{CI}$ & P-value & HR & $95 \% \mathrm{CI}$ & P-value \\
\hline RNF113A expression & 2.449 & $1.351-4.439$ & 0.003 & 2.406 & $1.301-4.449$ & 0.005 \\
\hline Sex & 0.882 & $0.465-1.670$ & 0.699 & 0.826 & $0.420-1.627$ & 0.581 \\
\hline Age & 0.685 & $0.410-1.144$ & 0.148 & 1.387 & $0.720-2.675$ & 0.328 \\
\hline Tumor location & 1.624 & $0.716-3.685$ & 0.457 & 1.068 & $0.578-1.970$ & 0.593 \\
\hline Histological type & 1.187 & $0.476-2.956$ & 0.711 & 0.079 & $0.205-1.191$ & 0.254 \\
\hline Tumor differentiation & 1.491 & $0.840-3.012$ & 0.132 & 1.254 & $0.563-2.793$ & 0.748 \\
\hline T classification & 1.798 & $1.040-3.110$ & 0.036 & 1.205 & $0.564-2.577$ & 0.63 \\
\hline Lymph node metastasis & 3.154 & $1.882-5.285$ & $<0.001$ & 3.219 & $1.894-5.469$ & $<0.001$ \\
\hline
\end{tabular}

ESCC, esophageal squamous cell carcinoma; RNF113A, ring finger protein 113A; HR, hazard ratio; 95\% CI, 95\% confidence interval. Values in bold font indicate statistical significance $(\mathrm{P}<0.05)$.

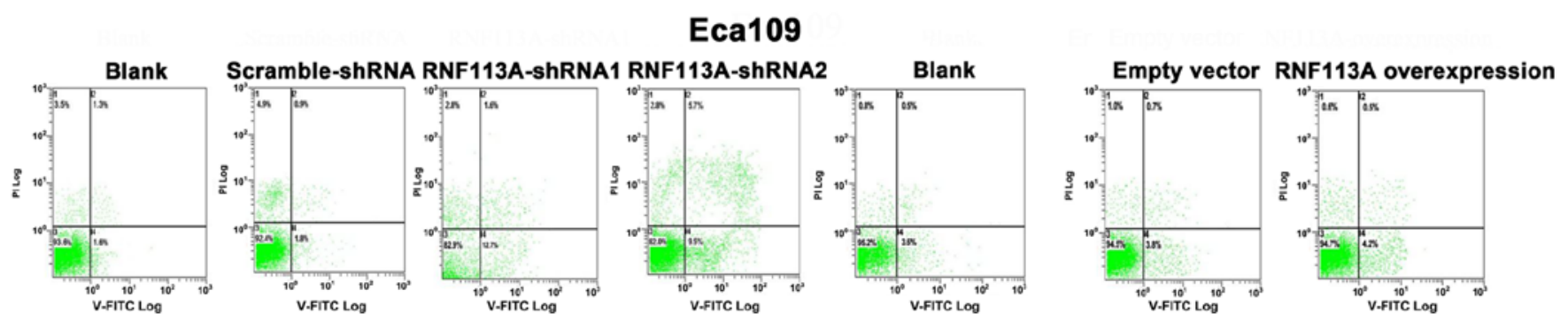

EC9706
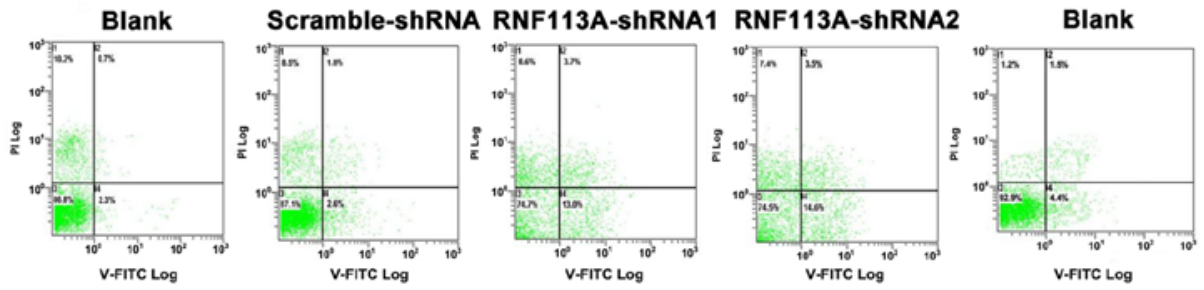

Empty vector RNF113A overexpression
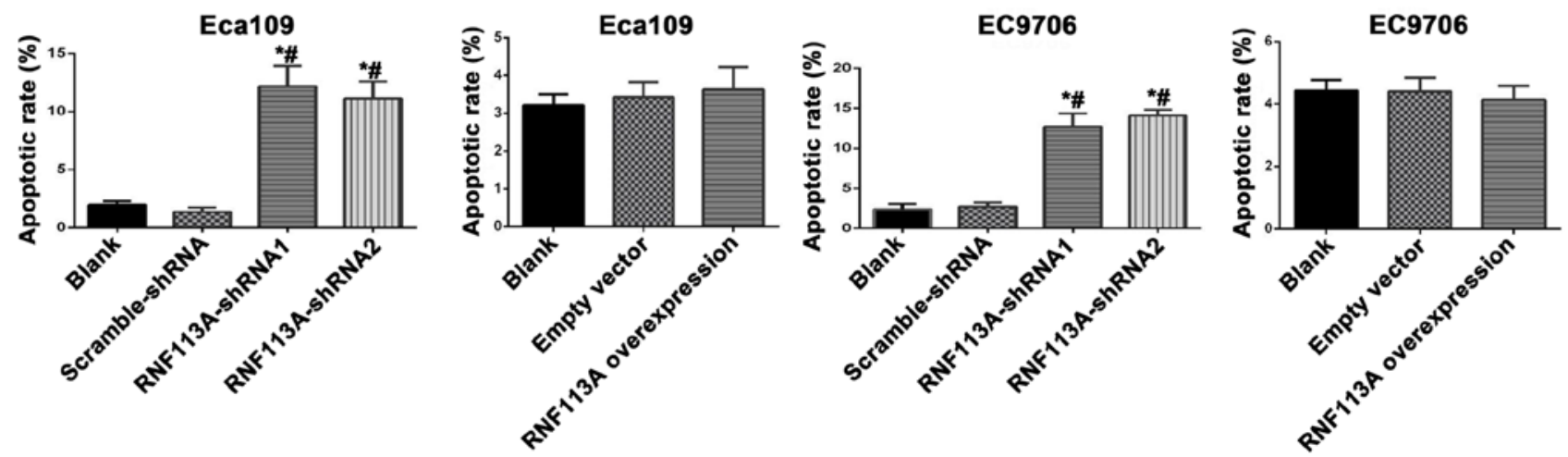

Figure 4. Effects of the knockdown or overexpression of ring finger protein 113A (RNF113A) on the apoptosis of Eca109 and EC9706 cells. The Eca109 and EC9706 cells were transfected with lentivirus-mediated RNF113A-shRNA1, RNF113A-shRNA2, and scramble-shRNA for $72 \mathrm{~h}$. Eca109 and EC9706 cells were transfected with empty vector (pcDNA3.1) or RNF113A overexpression vector for $72 \mathrm{~h}$. Cell apoptosis was determined by flow cytometry using Annexin V/PI staining. The quadrants in the flow cytometry plots are as follows: Upper left, necrotic cells; bottom left, live cells; upper right, late apoptotic cells; and lower right, early apoptotic cells. Data are presented as mean \pm SD of 3 independent experiments performed in triplicate. ${ }^{*} \mathrm{P}<0.05$ vs. blank group; ${ }^{\#} \mathrm{P}<0.05$ vs. scramble-shRNA or empty vector group.

cells (all $\mathrm{P}<0.05$ ) (Fig. 8A and B). RT-qPCR and IHC confirmed that the RNF113A mRNA and protein levels were downregulated in the sections of the subcutaneous tumors of nude mice inoculated with RNF113A-shRNA-transfected cells, compared with the untransfected Eca109 cells and scramble-shRNA-transfected cells (Fig. 8C and D). 


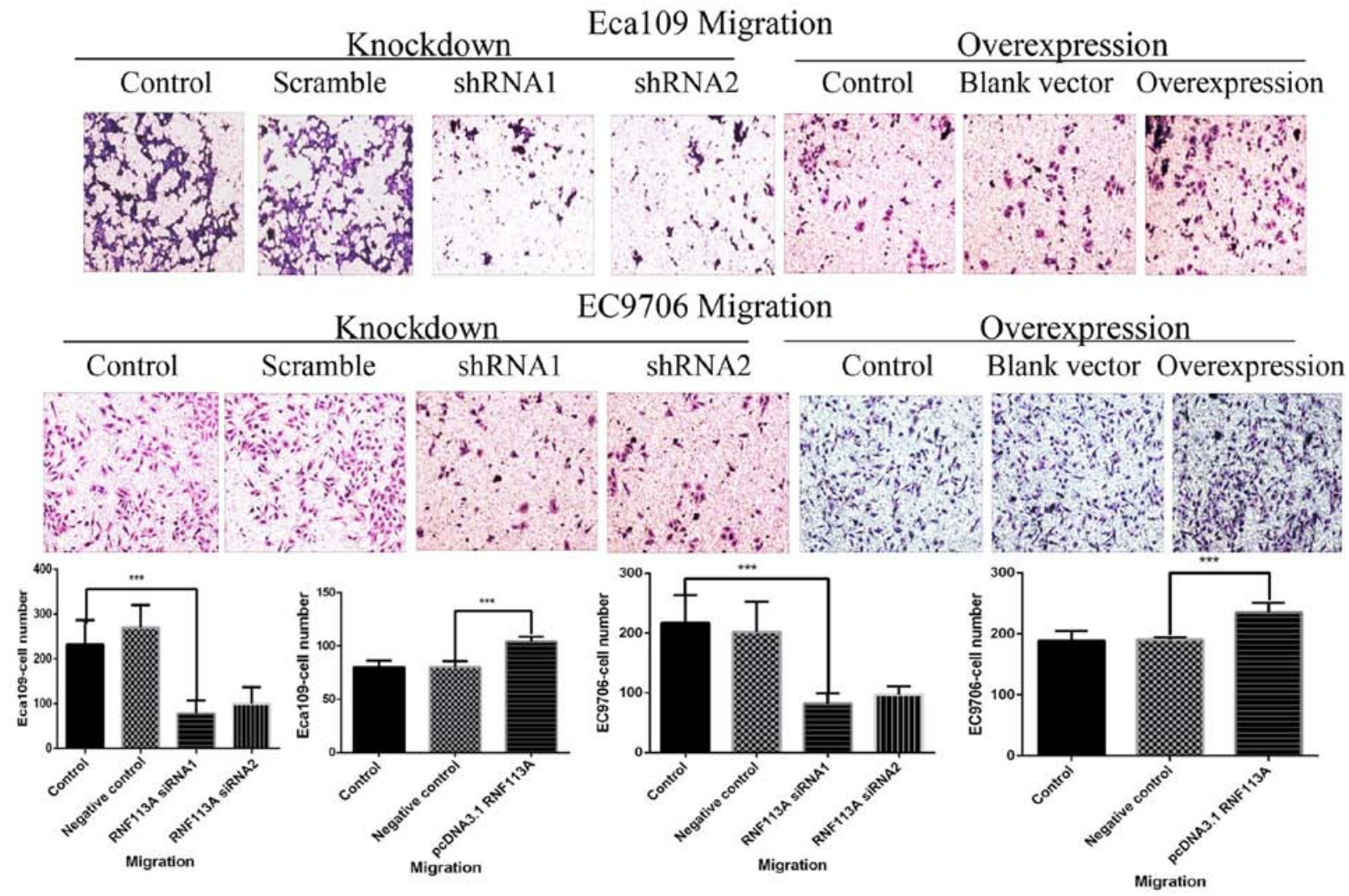

Figure 5. Effect of the knockdown and the overexpression of ring finger protein 113A (RNF113A) on the migration of Eca109 and EC 9706 cells. Eca109 and EC9706 cells were transfected with lentivirus-mediated RNF113A-shRNA1, RNF113A-shRNA2, and scramble-shRNA for 72 h. Eca109 and EC9706 cells were transfected with empty vector (pcDNA3.1) or RNF113A overexpression vector for $72 \mathrm{~h}$. Migration was assessed by Transwell assay. Data are presented as the means $\pm \mathrm{SD}$ of 3 independent experiments performed in triplicate. ${ }^{* * *} \mathrm{P}<0.001$ vs. blank group; ${ }^{\# \# \#} \mathrm{P}<0.001$ vs. scramble-shRNA or empty vector group.
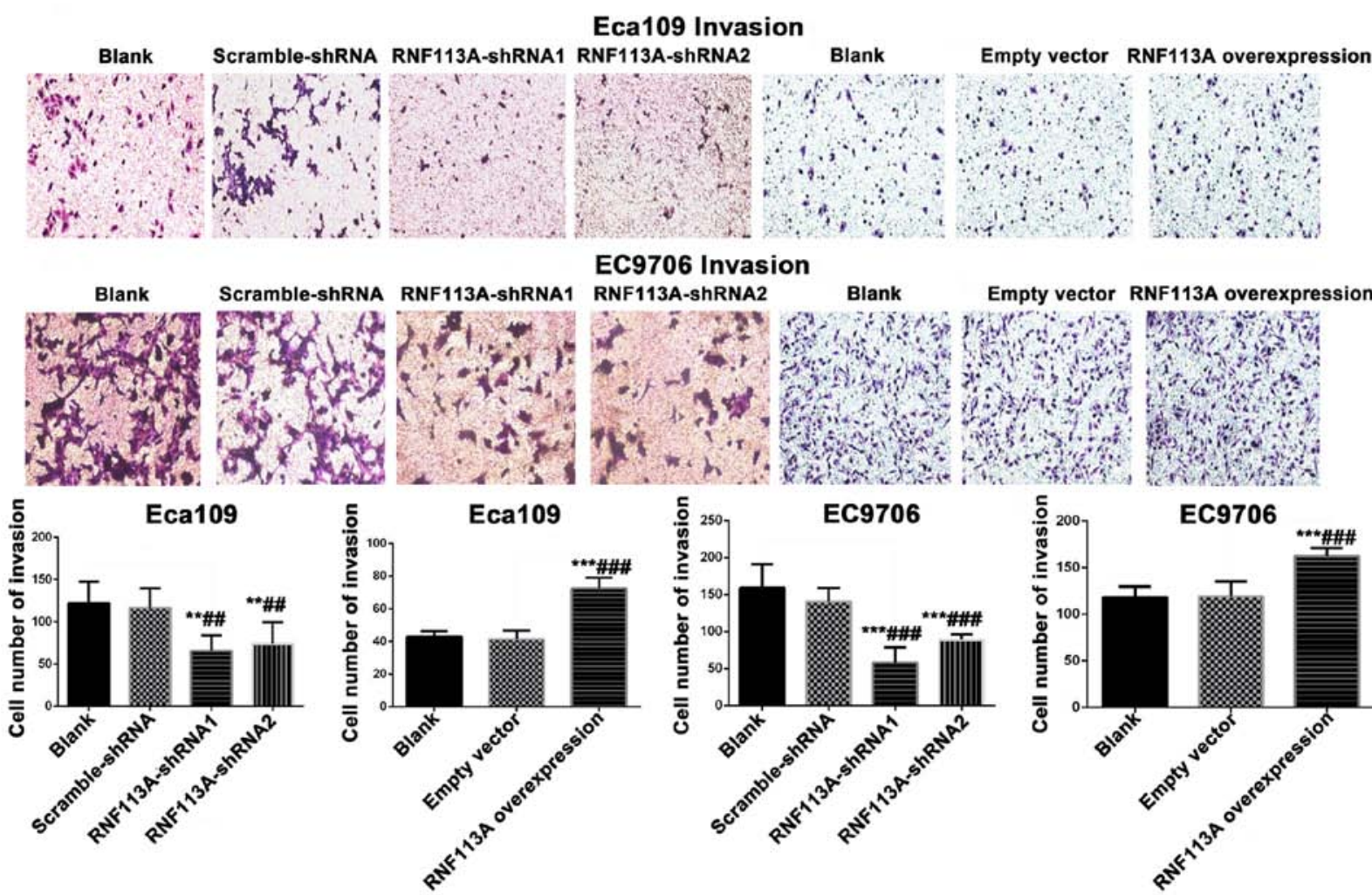

Figure 6. Effects of the knockdown or overexpression of ring finger protein 113A (RNF113A) on the invasion of Eca109 and EC 9706 cells. Eca109 and EC9706 cells were transfected with lentivirus-mediated RNF113A-shRNA1, RNF113A-shRNA2, and scramble-shRNA for $72 \mathrm{~h}$. Eca109 and EC 9706 cells were transfected with empty vector (pcDNA3.1) or RNF113A overexpression vector for $72 \mathrm{~h}$. Invasion was assessed by Transwell assay. Data are presented as the means \pm SD of 3 independent experiments performed in triplicate. ${ }^{* *} \mathrm{P}<0.01$ and ${ }^{* * *} \mathrm{P}<0.001$ vs. blank group; ${ }^{\# \#} \mathrm{P}<0.01$ and ${ }^{\# \#} \mathrm{P}<0.001$ vs. scramble-shRNA or empty vector group. 

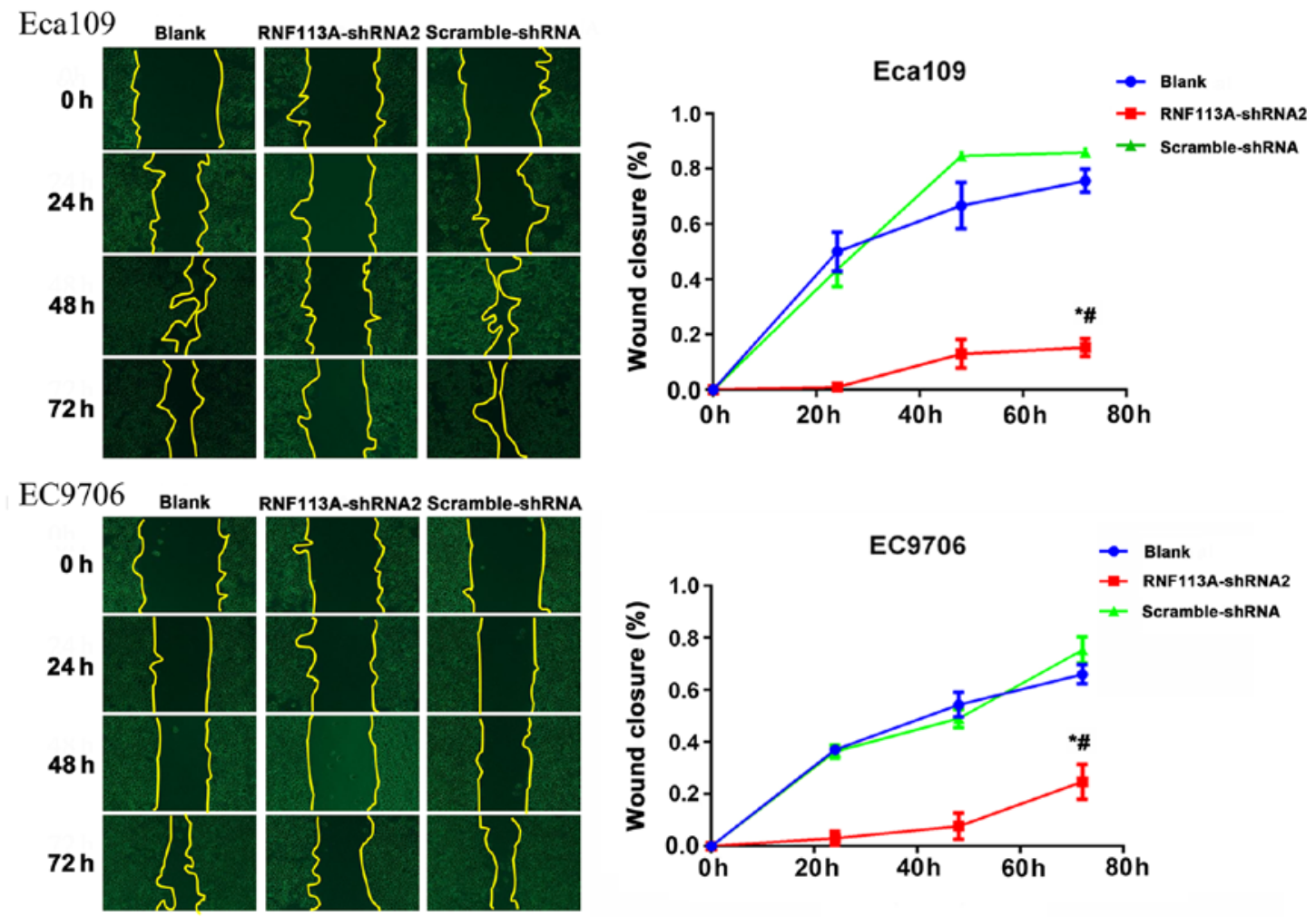

Figure 7. Effects of ring finger protein 113A (RNF113A) knockdown on the migration of Eca109 and EC 9706 cells. Eca109 and EC9706 cells were transfected with lentivirus-mediated RNF113A-shRNA and scramble-shRNA for $72 \mathrm{~h}$. Then migration was assessed by the wound healing assay at $0,24,48$ and $72 \mathrm{~h}$. Data are presented as mean $\pm \mathrm{SD}$ of 3 independent experiments performed in triplicate. ${ }^{\mathrm{P}}<0.05$ vs. blank group; ${ }^{*} \mathrm{P}<0.05$ vs. scramble-shRNA.

A

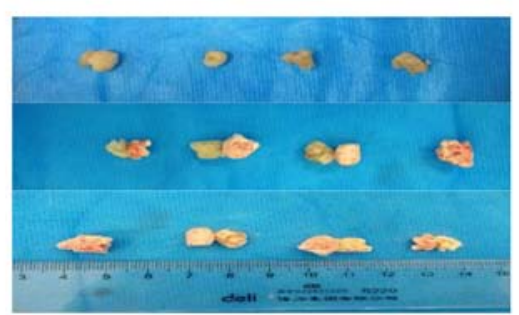

в
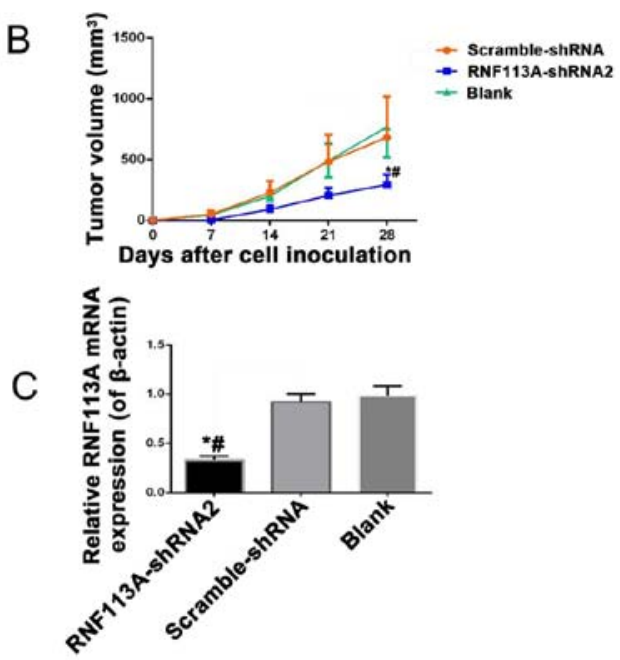

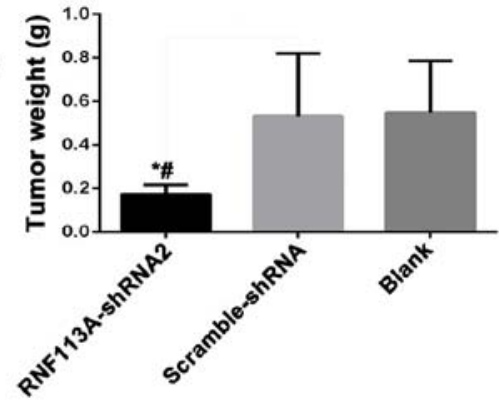

D

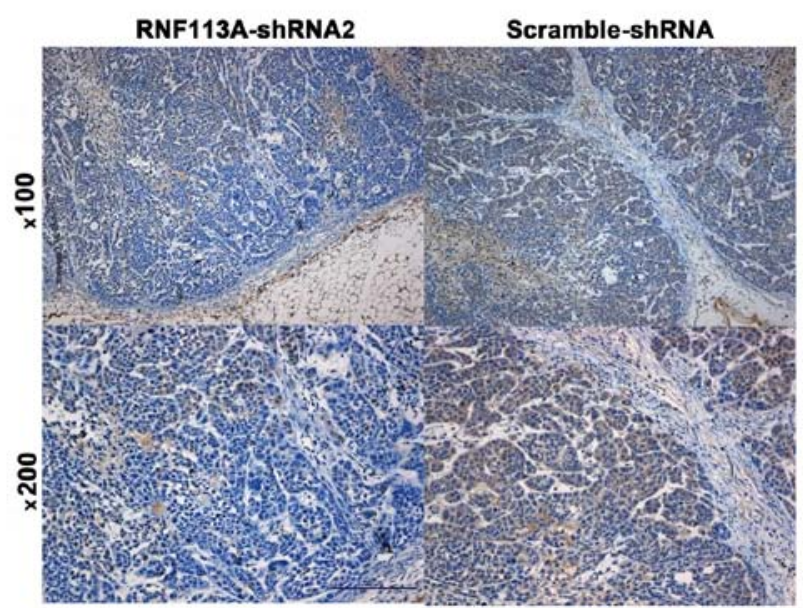

Figure 8. Effects of ring finger protein 113A (RNF113A) knockdown on tumor growth in vivo. Eca109cells transfectedwith lentivirus-mediated RNF113A-shRNA and scramble-shRNA ( $4 \times 10^{6}$ cells) were subcutaneously inoculated into the right dorsal flanks of BALB/c nude mice. Eca109 cells were used as a blank control group. (A) Tumor size and weight (g) was measured 28 days after inoculation. (B) Tumor volume $\left(\mathrm{mm}^{3}\right)$ was assessed by calipers each week. (C) RNF113A mRNA expression in the tumor tissues was determined by RT-qPCR. (D) RNF113A protein expression in the tumor tissues was determined by immunohistochemistry. Data are presented as the means $\pm \mathrm{SD}$ ( $\mathrm{n}=4$ /group). ${ }^{*} \mathrm{P}<0.05$ vs. blank group; ${ }^{\prime \prime} \mathrm{P}<0.05$ vs. scramble-shRNA. 


\section{Discussion}

The UPP influences and regulates apoptosis and plays a central role in the binding of ubiquitin and substrate specificity (9). E3 ligases are involved in Snail and Twist ubiquitination, which play important roles in EMT $(10,11)$. RNF113A has a RING domain (14), which is frequently found in E3 ubiquitin ligases. Previous studies have indicated that there are close associations between ubiquitin ligase and the occurrence, development and metastasis of cancer $(16,17)$. In C. elegans, the knockdown of RNF113 sensitizes the cells to UVA-induced DNA damage and is required for RAD51 during repair (19). Pellagatti et al (20) showed that ZNF183 was one of the most upregulated genes in MDS (20). Therefore, it can be hypothesized that RNF113A is associated with the progression/development of ESCC. Nevertheless, little is known about the expression of RNF113A in ESCC and its significance.

The present study demonstrated that RNF113A expression was associated with the $\mathrm{T}$ stage, suggesting that it may be associated with tumorigenesis, as well as tumor progression. RT-qPCR revealed that the overexpression of RNF113A in 73\% of ESCC samples, supporting the results of IHC. Kaplan-Meier analysis revealed a poorer survival rate in patients with ahigh RNF113A expression. Furthermore, multivariate analysis revealed that the RNF113A levels could be used as an independent prognostic factor for patients with ESCC. Therefore, RNF113A may be a novel diagnostic and prognostic biomarker for ESCC, although this requires further validation. Nevertheless, these results are supported by previous studies of various RING finger proteins in various cancer types (31-34).

Cell cycle progression, the inhibition of apoptosis, and cell migration and invasion are central features of ESCC progression (26,35-37). Supporting the role of RNF113A in ESCC aggressiveness, the present study demonstrated that the overexpression of RNF113A was associated with cell cycle progression and an increased migration and invasiveness of Eca109 and EC9706 cells. These results are similar to those observed with various RING finger proteins in various cancer types. Yonemori et al (38) showed that ZFP36L2 promoted cancer cell proliferation, migration and invasion in pancreatic ductal adenocarcinoma. Zhang and Yang (39) showed that silencing tripartite motif containing 59 (TRIM59) inhibited the proliferation, migration and invasion of breast cancer cells. Similar results were also observed in gastric cancer with RNF180 (40) and colorectal cancer with RNF216 (41). These results support the roles of RING finger proteins in carcinogenesis. Tumor metastasis is one of the most important biological characteristics of malignant tumors, and metastasis is a strong independent prognostic factor for ESCC (42). In this study, RNF113A expression was not associated with lymph node metastasis as revealed the examination of tumor samples; however, in vitro experiments suggested that RNF113A may promote the migration and invasiveness of ESCC cell lines. The exact role of RNF113A in the advanced stage of ESCC remains to be through analyzed in the future, based on clinical studies with an enlarged sample size and in vitro studies using a greater number of cell lines.

The exact mechanisms responsible for the effects of RNF113A on cancer progression are poorly understood and further investigations are warranted. Nevertheless, some previous studies may provide some clues. The normal expression of RNF113A plays an important role in the differentiation of cells of the central nervous system during embryogenesis (15). RNF113A participates in the regulation of the stability of proteins of the E2 and E3 families (15). EMT is a hallmark of cancer invasiveness and the regulation of the stability of the transcription factors involved in EMT is essential to this process $(10,11)$. Among others, ubiquitin ligases controlling Snail and Twist stability plays crucial role in EMT (11). Indeed, Snail and Twist are short-lived due to rapid polyubiquitination in normal cells and E3 is involved in this process (11). The degradation of most EMT factors depends upon RING-type E3s. In addition, RNF113A has a C3HC4 zinc finger domain, which is found in E3 ubiquitin ligase and is involved in tumorigenesis $(11,43,44)$. Furthermore, other proteins of the family are known to be involved in tumorigenesis. Indeed, RNF183 promotes the proliferation and metastasis of colorectal cancer cells via the activation of the NF-kB-IL-8 axis (45). RNF125 is a potential biomarker for the highly aggressive and unfavorable prognosis of gallbladder cancers by promoting the invasion and metastasis of human gallbladder cancers via the activation of the TGF- $\beta 1$-SMAD3-ID1 signaling pathway (46). Cancer progression and cell proliferation, migration and invasion are orchestrated by a very complex and interwoven array of molecules. Two approaches are available to study these interactions: Either the use of bioinformatics to grasp a global view of the processes, or the study of a single specific factor. The present study aimed to assess the effect of RNF113A on the progression of ESCC. The results indeed demonstrated that RNF113A plays an important role in ESCC progression; however, the mechanisms through which this factor interacts with other factors remain to be elucidated.

The present study is not without limitations. The sample size was small and from a single center. In addition, all patients were Kazakh, which is a Chinese minority that has the highest incidence of ESCC worldwide (6); however, this limits the generalizability of the results. It is probable that this high incidence is due to a number of environmental and genetic factors that may influence the results of the present study. Additional studies on various populations are warranted to confirm these results. The mechanisms through which RNF113A promotes malignant behaviors in vitro required further investigation.

In conclusion, the present study strongly suggests that RNF113A promotes the proliferation, migration and invasion of ESCC cells, and that RNF113A is associated with a poor prognosis of ESCC in Kazakh patients.

\section{Acknowledgements}

This study was funded by Major Projects in the Xinjiang Uygur Autonomous Region (no. 2016B03054).

\section{Competing interests}

The authors declare that they have no competing interests.

\section{References}

1. Parkin DM, Pisani P and Ferlay J: Global cancer statistics. CA Cancer J Clin 49: 33-64, 31, 1999. 
2. Chen W, Zheng R, Zeng H, Zhang S and He J: Annual report on status of cancer in China, 2011. Chin J Cancer Res 27: 2-12, 2015.

3 . Yang CS, Chen X and Tu S: Etiology and prevention of esophageal cancer. Gastrointest Tumors 3: 3-16, 2016.

4. Siegel RL, Miller KD and Jemal A: Cancer Statistics, 2017. CA Cancer J Clin 67: 7-30, 2017.

5. Arnold M, Soerjomataram I, Ferlay J and Forman D: Global incidence of oesophageal cancer by histological subtype in 2012 . Gut 64: 381-387, 2015

6. Ainiwaer J, Li DS and Zhang L: Investigation on prevalence of esophageal cancer during 2005-2008 in Yili of Xinjiang, China. Xinjiang Medical J 41: 112-114, 2011.

7. NCCN Clinical Practice Guidelines in Oncology (NCCN Guidelines): Esophageal and Esophagogastric Junction Cancers. Version 2.2017. National Comprehensive Cancer Network, Fort Washington, 2017.

8. Mukhopadhyay D and Riezman H: Proteasome-independent functions of ubiquitin in endocytosis and signaling. Science 315 201-205, 2007.

9. Sullivan JA, Shirasu K and Deng XW: The diverse roles of ubiquitin and the $26 \mathrm{~S}$ proteasome in the life of plants. Nat Rev Genet 4: 948-958, 2003.

10. Xue Z, Wu X, Chen X, Liu Y, Wang X, Wu K, Nie Y and Fan D Mesenchymal stem cells promote epithelial to mesenchymal transition and metastasis in gastric cancer though paracrine cues and close physical contact. J Cell Biochem 116: 618-627, 2015.

11. Díaz VM, Viñas-Castells R and García de Herreros A: Regulation of the protein stability of EMT transcription factors. Cell Adhes Migr 8: 418-428, 2014.

12. Corbett MA, Dudding-Byth T, Crock PA, Botta E, Christie LM, Nardo T, Caligiuri G, Hobson L, Boyle J, Mansour A, et al: A novel X-linked trichothiodystrophy associated with a nonsense mutation in RNF113A. J Med Genet 52: 269-274, 2015.

13. Frattini A, Faranda S, Bagnasco L, Patrosso C, Nulli P, Zucchi I and Vezzoni P: Identification of a new member (ZNF183) of the Ring finger gene family in Xq24-25. Gene 192: 291-298, 1997.

14. Korneta I, Magnus M and Bujnicki JM: Structural bioinformatics of the human spliceosomal proteome. Nucleic Acids Res 40: 7046-7065, 2012.

15. Carney TD, Struck AJ and Doe CQ: midlife crisis encodes a conserved zinc-finger protein required to maintain neuronal differentiation in Drosophila. Development 140: 4155-4164, 2013.

16. Bromberg KD, Kluger HM, Delaunay A, Abbas S, DiVito KA, Krajewski S and Ronai Z: Increased expression of the E3 ubiquitin ligase RNF5 is associated with decreased survival in breast cancer. Cancer Res 67: 8172-8179, 2007

17. Chen C, Sun X, Guo P, Dong XY, Sethi P, Zhou W, Zhou Z, Petros J, Frierson HF Jr, Vessella RL, et al: Ubiquitin E3 ligase WWP1 as an oncogenic factor in human prostate cancer. Oncogene 26: 2386-2394, 2007.

18. Amsterdam A, Nissen RM, Sun Z, Swindell EC, Farrington S and Hopkins N: Identification of 315 genes essential for early zebrafish development. Proc Natl Acad Sci USA 101: 12792-12797, 2004.

19. Lee H, Alpi AF, Park MS, Rose A and Koo HS: C. elegans ring finger protein RNF-113 is involved in interstrand DNA crosslink repair and interacts with a RAD51C homolog. PLoS One 8 e60071, 2013.

20. Pellagatti A, Esoof N, Watkins F, Langford CF, Vetrie D, Campbell LJ, Fidler C, Cavenagh JD, Eagleton H, Gordon P, et al: Gene expression profiling in the myelodysplastic syndromes using cDNA microarray technology. Br J Haematol 125: 576-583, 2004.

21. Heath-Brown N: International Union Against Cancer. In: The Stateman's Yearbook 2016. Palgrave MacMillan, London, 2015.

22. Ma JQ, Tuersun H, Jiao SJ, Zheng JH, Xiao JB and Hasim A: Functional role of NRF2 in cervical carcinogenesis. PLoS One 10: e0133876, 2015.

23. Sinicrope FA, Ruan SB, Cleary KR, Stephens LC, Lee JJ and Levin B: Bcl-2 and p53 oncoprotein expression during colorectal tumorigenesis. Cancer Res 55: 237-241, 1995.

24. Zhu J, Li H, Ma J, Huang H, Qin J and Li Y: PTPN9 promotes cell proliferation and invasion in Eca109 cells and is negatively regulated by microRNA-126. Oncol Lett 14: 1419-1426, 2017.

25. Chen HX, Wang S, Wang Z, Zhang ZP and Shi SS: Overexpression of RUNX3 inhibits malignant behaviour of Eca109 cells in vitro and in vivo. Asian Pac J Cancer Prev 15: 1531-1537, 2014.

26. Li S, Wang F, Qu Y, Chen X, Gao M, Yang J, Zhang D, Zhang N, Li W and Liu H: HDAC2 regulates cell proliferation, cell cycle progression and cell apoptosis in esophageal squamous cell carcinoma EC9706 cells. Oncol Lett 13: 403-409, 2017.
27. Sun Z, Ji N, Bi M, Wang S, Liu X and Wang Z: PTEN gene is infrequently hypermethylated in human esophageal squamous cell carcinoma. Tumour Biol 36: 5849-5857, 2015.

28. Wang T, Xuan X, Pian L, Gao P, Hu H, Zheng Y, Zang W and Zhao G: Notch-1-mediated esophageal carcinoma EC-9706 cell invasion and metastasis by inducing epithelial-mesenchymal transition through Snail. Tumour Biol 35: 1193-1201, 2014.

29. Cory G: Scratch-wound assay. Methods Mol Biol 769: 25-30, 2011.

30. Jonkman JE, Cathcart JA, Xu F, Bartolini ME, Amon JE, Stevens KM and Colarusso P: An introduction to the wound healing assay using live-cell microscopy. Cell Adhes Migr 8: 440-451, 2014

31. Sugiura T, Yamaguchi A and Miyamoto K: A cancer-associated RING finger protein, RNF43, is a ubiquitin ligase that interacts with a nuclear protein, HAP95. Exp Cell Res 314: 1519-1528, 2008.

32. Zhu J, Zhao C, Zhuang T, Jonsson P, Sinha I, Williams C, Strömblad S and Dahlman-Wright K: RING finger protein 31 promotes $\mathrm{p} 53$ degradation in breast cancer cells. Oncogene 35: $1955-1964,2016$

33. Horie K, Urano T, Ikeda K and Inoue S: Estrogen-responsive RING finger protein controls breast cancer growth. J Steroid Biochem Mol Biol 85: 101-104, 2003.

34. Oyanagi H, Takenaka K, Ishikawa S, Kawano Y, Adachi Y, Ueda K, Wada H and Tanaka F: Expression of LUN gene that encodes a novel RING finger protein is correlated with development and progression of non-small cell lung cancer. Lung Cancer 46: 21-28, 2004

35. Zhang Y,Zhang Y, Yun H, Lai R and Su M: Correlation of STAT1 with apoptosis and cell-cycle markers in esophageal squamous cell carcinoma. PLoS One 9: e113928, 2014.

36. Bozzuto G, Ruggieri P and Molinari A: Molecular aspects of tumor cell migration and invasion. Ann Ist Super Sanita 46: 66-80, 2010.

37. Friedl $P$ and Wolf K: Tumour-cell invasion and migration: Diversity and escape mechanisms. Nat Rev Cancer 3: 362-374, 2003.

38. Yonemori K, Seki N, Kurahara H, Osako Y, Idichi T, Arai T, Koshizuka K, Kita Y, Maemura K and Natsugoe S: ZFP36L2 promotes cancer cell aggressiveness and is regulated by antitumor microRNA-375 in pancreatic ductal adenocarcinoma. Cancer Sci 108: 124-135, 2017.

39. Zhang Y and Yang WB: Down-regulation of tripartite motif protein 59 inhibits proliferation, migration and invasion in breast cancer cells. Biomed Pharmacother 89: 462-467, 2017.

40. Deng J, Liang H, Zhang R, Hou Y, Liu Y, Ying G, Pan Y and Hao X: Clinical and experimental role of ring finger protein 180 on lymph node metastasis and survival in gastric cancer. Br J Surg 103: 407-416, 2016.

41. Wang H, Wang Y, Qian L, Wang X, Gu H, Dong X, Huang S, Jin M, Ge H, Xu C, et al: RNF216 contributes to proliferation and migration of colorectal cancer via suppressing BECN1-dependent autophagy. Oncotarget 7: 51174-51183, 2016.

42. Ando N, Kato H, Igaki H, Shinoda M, Ozawa S, Shimizu H, Nakamura T, Yabusaki H, Aoyama N, Kurita A, et al: A randomized trial comparing postoperative adjuvant chemotherapy with cisplatin and 5-fluorouracil versus preoperative chemotherapy for localized advanced squamous cell carcinoma of the thoracic esophagus (JCOG9907). Ann Surg Oncol 19: 68-74, 2012

43. Lazzari E and Meroni G: TRIM32 ubiquitin E3 ligase, one enzyme for several pathologies: From muscular dystrophy to tumours. Int J Biochem Cell Biol 79: 469-477, 2016.

44. Cai W and Yang H: The structure and regulation of Cullin 2 based E3 ubiquitin ligases and their biological functions. Cell Div 11: 7, 2016.

45. Geng R, Tan X, Wu J, Pan Z, Yi M, Shi W, Liu R, Yao C, Wang G, Lin J, et al: RNF183 promotes proliferation and metastasis of colorectal cancer cells via activation of NF- $\kappa \mathrm{B}-\mathrm{IL}-8$ axis. Cell Death Dis 8: e2994, 2017

46. Liu ZY, Cao J, Zhang JT, Xu GL, Li XP, Wang FT, Ansari KH, Mohamed $\mathrm{H}$ and Fan YZ: Ring finger protein 125, as a potential highly aggressive and unfavorable prognostic biomarker, promotes the invasion and metastasis of human gallbladder cancers via activating the TGF- $\beta 1$-SMAD3-ID1 signaling pathway. Oncotarget 8 49897-49914, 2017 